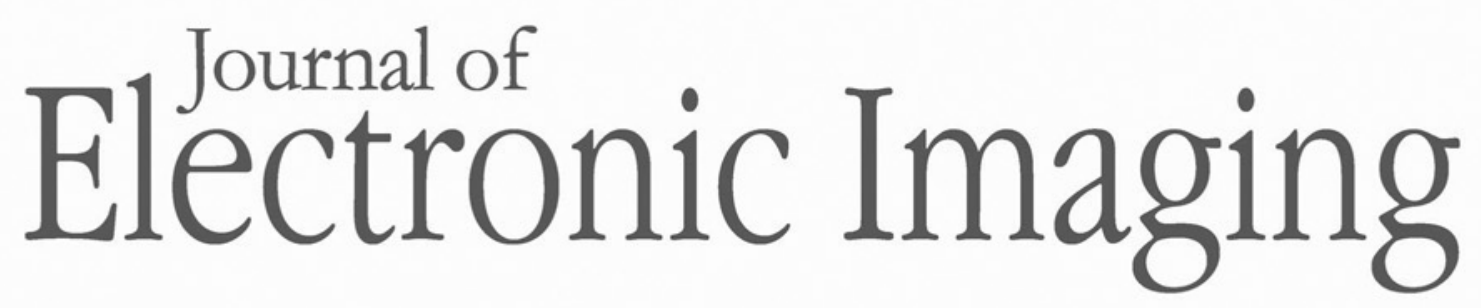

JElectroniclmaging.org

\title{
Changing Times
}

\author{
Gaurav Sharma
}




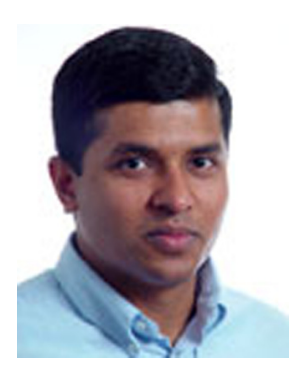

\section{Changing Times}

The Journal of Electronic Imaging (JEI) has a new editor. In January 2016, I handed over the reins of JEI to Karen Egiazarian. I remain committed to the journal and to its success; my decision to step down comes more from my strong belief in reasonable terms for such leadership appointments. Having completed five years as editor, I felt it would be best for the journal to have someone new at the helm with fresh energy and ideas to further strengthen the journal. It will also be good for me to have some of my time back for my own new initiatives and directions.

During my time as editor, JEI saw very significant growth. The number of submissions we received grew over threefold, going from 197 submissions in 2010, before I took over, to 711 submissions in 2015, the last year of my term. The number of published papers has also grown from 108 in 2010 to 215 in 2015. With the increased volume of publications, JEl also achieved an important landmark, going from publishing an issue once a quarter to once every two months-a change that took effect as of January 2014. At the same time, JEI has become much more efficient and selective. Times to first decision and, for accepted papers, the time from submission to final publication have both also gone down significantly and our current acceptance rate of around $28 \%$ is among the lowest in the history of the journal.

Initiatives that strengthen the journal and increase its visibility are a key responsibility for the editor. We pursued several such opportunities during my term as editor, although I wish I had more to report on this front. A key objective of mine was to develop closer cooperation between the journal and related conferences of the sponsoring societies, SPIE and IS\&T. Fortuitously, I was cochair and chair, respectively, for the Electronic Imaging Symposia in 2012 and 2013, which were cosponsored by SPIE and IS\&T, and whose scope aligns extremely well with the journal. I therefore availed myself of the opportunity to better exploit the synergy between the journal and these symposia. Authors wishing to submit to the journal and the symposium were offered a journal-first option where authors could exercise the choice of submitting an article to JEI, which, if accepted for JEI, would also be accepted into the symposium program for presentation at a suitable conference in the symposium. Additionally, authors whose work appeared in the journal in the past year were also offered the opportunity to present their work at the symposium to gain better visibility for their work. This new effort drew a moderate response from the community. Additionally, we also continued to pursue collaborations with conferences through special sections of the journal. Between these and other special sections, JEl had a steady stream of special sections during my tenure. There were a total of nine special sections covering diverse areas: two each on stereoscopic displays and applications and quality control by artificial vision, and one each on mobile computational photography, compressive sensing for imaging, video surveillance and transportation imaging applications, image/video quality and system performance, and ultrawide context- and content-aware imaging, the last one being a two-part special section appearing over two issues. These special sections add to the vitality of the journal by showcasing emerging areas as well as by highlighting new developments in established areas. Additionally, JEl also published six tutorials/surveys during my term as editor. I was hoping for a much larger number, but getting established researchers to devote the time required to write authoritative and comprehensive surveys/tutorials turned out to be a much harder task than I anticipated!

A trend that began prior to my tenure and one that continues unabated is the increasing internationalization of the journal. Over ninety percent of our submissions now come from outside North America, often from the developing regions of the world. As someone whose own roots lie in India, a developing nation, I am thrilled to see the increased participation in science and technology and increasing democratization of research. What has not been so exciting, however, is the affiliated problematic trend of an increasing number of cases of author ethics violations. Each of these violations are rather time-consuming and energy-draining to handle, with end outcomes that are not productive for anyone. My role as editor brought me to the forefront of this issue and also made me realize that while deliberate instances of plagiarism and fraud are seen on occasion, an increasing number of ethics violations today are arising because many authors in the developing world lack a clear understanding of what is acceptable conduct in scientific publishing. Prompted by this realization, I initiated a personal campaign of author education in developing regions. When invited to speak on a technical topic in developing countries, I usually also insist on doing another talk on this important issue. The gratitude conveyed by student participants in these sessions has been particularly satisfying and I am also happy to see emerging institutional support for such author education initiatives from professional organizations, in several of whose efforts I continue to participate. In the context of the journal, I also had the pleasure to work with other SPIE journal editors as part of the SPIE board of editors in updating ethics policy statements so that they are easier to understand and follow.

Serving in the role of editor for JEI has been an extremely positive experience for me. I have had the pleasure to interact with a number of dedicated colleagues and with staff members from both SPIE and IS\&T and have gained a lot from these interactions. I owe a personal debt of gratitude to everyone who served on the JEl editorial board under my editorship. I thoroughly appreciate everything you have done and what (several of) you continue to do for the journal and take pride in what we collectively accomplished-thank you! My heartfelt thanks to Karolyn Labes, who served as managing editor for JEI throughout my term. Her responsiveness and professionalism is such that only in my second year as editor did I realize that JEI does not have an exclusive claim on her time and that she also serves in this role for all other SPIE journals! I would also like to convey my sincere appreciation to Eric Pepper, SPIE director of publications, for his sage advice on many matters and ever patient and professional collaboration in dealing with the ethics cases that we handled jointly. Thanks also to Gwen Weerts at SPIE for all her efforts in support of special sections and to Brenda McDonald for ensuring that day-to-day operations ran smoothly and matters that needed my attention stayed on my radar despite my many other preoccupations. To Suzanne Grinnan, executive director of IS\&T, I owe a debt of gratitude for her friendship and for her enthusiastic support for new initiatives and directions. Last but not least, my thanks to the authors and readers for JEl; without them the journal cannot exist.

The journal is in good hands with Karen, with whom I had the pleasure of working closely to architect the transition over the last quarter of 2015. I look forward with excitement to what JEI will bring next. 